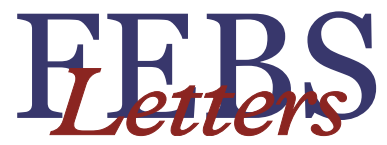

journal homepage: www.FEBSLetters.org

\title{
Scavenger receptor B1 post-translational modifications in Rett syndrome
}

\author{
${ }^{a}$ Department of Life Sciences and Biotechnology, University of Ferrara, Ferrara, Italy \\ ${ }^{\mathrm{b}}$ Department of Biomedical Sciences, University of Siena, Siena, Italy \\ ${ }^{\mathrm{c}}$ Department of Molecular and Developmental Medicine, University of Siena, Siena, Italy \\ ${ }^{\mathrm{d}}$ Child Neuropsychiatry Unit, University Hospital, Azienda Ospedaliera Universitaria Senese (AOUS), Siena, Italy \\ e Neonatal Intensive Care Unit, University Hospital AOUS, Siena, Italy \\ ${ }_{\mathrm{f}}^{\mathrm{f}}$ Department of Food and Nutrition, Kyung Hee University, Seoul, Republic of Korea
}

Claudia Sticozzi ${ }^{\text {a }}$, Giuseppe Belmonte ${ }^{\mathrm{b}}$, Alessandra Pecorelli ${ }^{\mathrm{c}}$, Franco Cervellati ${ }^{\mathrm{a}}$, Silvia Leoncini ${ }^{\mathrm{c}}$ Cinzia Signorini ${ }^{c}$, Lucia Ciccoli ${ }^{\mathrm{c}}$, Claudio De Felice ${ }^{\mathrm{d}}$, Joussef Hayek ${ }^{\mathrm{e}, 1}$, Giuseppe Valacchi ${ }^{\mathrm{a}, \mathrm{f}, *, 1}$

\section{A R T I C L E I N F O}

Article history:

Received 8 May 2013

Accepted 14 May 2013

Available online 24 May 2013

Edited by Barry Halliwell

\section{Keywords:}

Oxidative stress

4-Hydroxynonenal

Ubiquitination

Protein adducts

HDL

Cholesterol

\begin{abstract}
A B S T R A C T
The modulation of the HDL receptor scavenger receptor B1 (SRB1) was evaluated in skin fibroblasts isolated from patients with Rett syndrome (RTT), a genetic form of infantile autism. Patients showed an altered plasma lipid profile, while their skin fibroblasts showed a dramatic reduction in SRB1 (immunogold, Western blot and immunohistochemistry). The decreased SRB1 levels were demonstrated to be the consequence of its binding with 4-hydroxy-2-nonenal (4HNE), a product of lipid peroxidation, and its increased ubiquitination. Our findings show for the first time a loss of SRB1 in RTT cells and its relationship with a chronic oxidative stress status.
\end{abstract}

다 2013 Federation of European Biochemical Societies. Published by Elsevier B.V. All rights reserved.

\section{Introduction}

Rett syndrome (RTT), is a severe neurological disorder affecting almost exclusively females, with a frequency of approximately 1:10000 live births. Although it is a relatively rare condition, RTT represents the second most common cause of severe mental retardation in the female. In up to $95 \%$ of the cases causative mutations in the X-linked methyl-CpG binding protein 2 gene (MeCP2) are detectable, resulting in a wide genetical and phenotypical heterogeneity $[1,2]$. RTT is one of the so defined autism spectrum disorders (ASDs) and besides the "classic autism", includes Asperger syndrome and the pervasive developmental disorder not otherwise specified (PDD-NOS) [3]. Approximately half of the RTT patients do not reach 40 years of age due to a remarkably increased risk for sudden death [4]. Besides uncontrolled seizures, it is well known that cardiorespiratory complications and lung infections are the factors most strongly associated with an increased risk of sudden unexplained death in RTT [5].

\footnotetext{
* Corresponding author at: Department of Life Sciences and Biotechnologies, University of Ferrara, Via Luigi Borsari 46, 44100 Ferrara, Italy.

E-mail address: giuseppe.valacchi@unife.it (G. Valacchi)

1 These authors contributed equally to this work.
}

Emerging evidence indicates that abnormalities in fatty acid metabolism and membrane fatty acid composition may contribute to neurodevelopment disorders including ASDs [6]. At present, insufficient research exists regarding the lipid profile of girls with RTT. Dyslipidemia is the elevation of plasma cholesterol (T-Chol), triglycerides (TG), or both. We hypothesized that high-density lipoprotein (HDL) level may contribute to the vascular and/or respiratory complications observed in RTT [7-11]. However, to our knowledge, no information exists regarding the plasma lipid profile in RTT patients. Therefore, this study was conducted to analyze the lipid profile of RTT and evaluate the levels of the so called "HDL-receptor", better known as scavenger receptor B1 (SRB1) using primary skin fibroblasts isolated from RTT patients as a model. SRB1, a 82-kDa cell surface protein, is involved not only in the binding of HDL thus promoting selective uptake of HDL lipids via a hydrophobic channel, but it has now been shown that this receptor is also involved in several other cellular processes, such as recognition of pathogens and apoptotic cells, as well as lipid soluble antioxidants uptake; all conditions known to be present in the clinical picture of RTT patients. In addition, SRB1 can be modulated by oxidative stress (OS), either exogenous [12] or endogenous $[13,14]$, and the presence of chronic OS has been well documented 
in RTT [15] with a strong correlation between the levels of OS markers and disease severity $[16,17]$.

Therefore, in the present study, we hypothesized that RTT is associated with an altered plasma lipoprotein profile as a consequence of SRB1 modulation by OS.

\section{Methods}

\subsection{Subjects}

A total of 151 female patients with classical RTT disorder (mean age: $20.3 \pm 12.3$ ), as well as 50 healthy female controls of comparable age (mean age: $19.2 \pm 14.5$ ) participated to the study.

All the patients were consecutively admitted to the Child Neuropsychiatry Unit of the University Hospital of Siena (Head: J.H.). All the examined subjects were on a typical Mediterranean diet.

\subsection{Determination of serum lipids levels}

The subjects were fasted before taking the blood and serum lipids were measured using specific diagnostic kits (HDL-cholesterol plus 3rd generation and LDL-cholesterol plus 2nd generation, respectively, COBAS).

\subsection{Human skin fibroblast cultures}

Human skin fibroblasts were isolated from 3-mm skin punch biopsy ( $n=25$ for RTT and $n=15$ for controls). Cells were cultured in DMEM, containing 20\% fetal calf serum (FCS) and antibiotics (100 U/ml penicillin, $100 \mu \mathrm{g} / \mathrm{ml}$ streptomycin) (Lonza, Milan, Italy). Cells were incubated at $37{ }^{\circ} \mathrm{C}$ in a humidified atmosphere of $95 \%$ air and $5 \% \mathrm{CO}_{2}$ for 3 days. When fibroblasts growing from the dermal pieces formed a confluent layer, the dermal pieces were removed and trypsin/EDTA mixture was added to separate fibroblasts. Cells were transferred to $25-\mathrm{cm}^{2}$ culture flasks (Falcon, Perugia, Italy) and subcultured in 10\% FCS/DMEM. Fibroblasts from passage 3 to 5 were used for the experiments. For experiments with the proteasome inhibitor MG132 (Calbiochem, Mialno, Italy) the cells were either treated with or without MG132 (final concentration in culture $10 \mu \mathrm{M}$ ) dissolved in DMSO (final concentration in culture $0.01 \%$ ), and incubated for $2 \mathrm{~h}$ at $37^{\circ} \mathrm{C}$.

\subsection{Immunocytochemistry}

Fibroblasts were grown on coverslips at a density of $5 \times 10^{4}$ cell $/ \mathrm{ml}$, and then fixed in $4 \%$ paraformaldehyde in PBS for $30 \mathrm{~min}$ at $4{ }^{\circ} \mathrm{C}$ as previously described [18]. After permeabilization the coverslips were blocked in PBS (1\% BSA) at RT for $1 \mathrm{~h}$. Coverslips were then incubated with primary and then with secondary antibodies. Nuclei were stained with $1 \mu \mathrm{g} / \mathrm{ml}$ DAPI (Molecular Probes) after removal of secondary antibodies. Coverslips were examined by the Zeiss Axioplan2 light microscope equipped with epifluorescence at $40 \times$ magnification. Negative controls for the immunostaining experiments were performed by omitting primary antibodies. Images were acquired and analyzed with Axio Vision Release 4.6 .3 software.

\subsection{Western blot analysis}

Total cell lysates were extracted in RIPA buffer containing $50 \mathrm{mM}$ Tris ( $\mathrm{pH} 7.5$ ), $150 \mathrm{mM} \mathrm{NaCl}, 10 \%$ glycerol, $1 \%$ Nonidet P-40, 1 mM EGTA, 0.1\% SDS, 5 mM N-ethylmaleamide (SigmaAldrich Corp.), protease and phosphatase inhibitor cocktails (Sigma-Aldrich Corp.) as described before $[13,18]$.
Briefly, $60 \mu \mathrm{g}$ of boiled proteins were loaded onto $10 \%$ sodium dodecyl sulphate-polyacrylamide electrophoresis gels. The gels were electro-blotted onto nitrocellulose membranes and hen blocked for $1 \mathrm{~h}$ in 3\% milk. Membranes were incubated overnight at $4{ }^{\circ} \mathrm{C}$ with the primary antibody SRB1 (Novus Biologicals, Inc., Littleton, CO, USA) and with horseradish peroxidase-conjugated secondary antibody (BioRad, Milan, Italy). The blots were stripped and re-probed with $\beta$-actin (Cell Signalling; Celbio, Milan, Italy) as the loading control. Images of the bands were digitized and the densitometry of the bands were performed using Image-J software.

\subsection{Immunogold labelling}

Fibroblast cells $\left(1 \times 10^{6} \mathrm{cell} / \mathrm{ml}\right)$ were fixed, dehydrated and embedded in LR-White Resin Hard Grade (TAAB Laboratories, England, UK) as previously described [18]. For the immunogold labelling procedure, grids containing sections were incubated in $0.05 \mathrm{M}$ tris-buffered saline-Tween20 (TBST), pH 7.6, and free aldehyde binding was quench using $0.1 \mathrm{M}$ Glycine in $\mathrm{PB}$ and then non-specific protein binding was blocked using $5 \%$ NGS-1\% BSA in TBST. Samples were incubated overnight at $4{ }^{\circ} \mathrm{C}$ in anti-SRB1 (1:100) in $2 \%$ NGS-TBST. After treatment with primary antibody were washed and incubated in goat anti-rabbit IgG conjugated to $10 \mathrm{~nm}$ Gold particles (BBInternational, Cardiff, UK). The grids were post-fixed and rinsed in TBST, stained in aqueous uranyl acetate and lead citrate. The grids were examined and photographed using a Philips CM10 transmission electron microscope. For negative control, grids containing sections were incubated in $2 \%$ NGS-TBST without the primary antibody.

\subsection{Immunoprecipitation}

Cell lysates containing $500 \mu \mathrm{g}$ of protein were mixed with Dynabeads protein $\mathrm{G}$ and incubated with $2 \mu \mathrm{g}$ of polyclonal antibodies overnight at $4{ }^{\circ} \mathrm{C}$ in a total volume of $200 \mu \mathrm{l}$. The complexes were precipitated by incubation with protein A-agarose (Boehringer Mannheim) for $4 \mathrm{~h}$ at $4{ }^{\circ} \mathrm{C}$. Immunoprecipitates were washed five times with IP buffer and once with PBS and then separated by SDS-PAGE, electrotransferred to nitrocellulose membranes and immunoblotted.

\subsection{Statistical analysis}

For all the variables tested, one-way analysis of variance (ANOVA) was used. Statistical significance was indicated by a $P$-value $<0.05$. Data were expressed as mean \pm S.D. from triplicate determinations obtained in five separate experiments.

\section{Results}

\subsection{RTT subjects have high serum lipids levels}

As showed in Table 1, when compared to healthy subjects, RTT patients have a significant increase in total-cholesterol (12\%), LDLcholesterol (15\%) and HDL-cholesterol (18\%), respectively.

\subsection{SRB1 levels decrease in RTT subjects}

SRB1 has been shown to be involved in the cholesterol uptake from HDL and with less affinity from LDL, therefore we assessed the protein levels of SRB1 in both healthy subjects and RTT patients. As shown in Fig. 1A, fibroblasts isolated from RTT patients had significant lower levels in SRB1 protein (ca. 35\%, right panel) compared to the control. As shown in Fig. 1B, the different content 
Table 1

Serum lipids in Rett syndrome: comparisons with healthy controls (mean \pm S.D.).

\begin{tabular}{llll}
\hline & Rett & Healthy controls & $P$-Value \\
\hline$N$ & 151 & 50 & \\
Total cholesterol $(\mathrm{mg} / \mathrm{dl})$ & $186.9 \pm 36.2$ & $166 \pm 5.9$ & $0.0003^{* *}$ \\
Total triglycerides $(\mathrm{mg} / \mathrm{dl})$ & $80.9 \pm 33.9$ & $81.4 \pm 23.4$ & 0.9008 \\
LDL-cholesterol $(\mathrm{mg} / \mathrm{dl})$ & $102.2 \pm 31.3$ & $87.5 \pm 12.8$ & $0.0071^{* *}$ \\
HDL-cholesterol $(\mathrm{mg} / \mathrm{dl})$ & $60.1 \pm 18.2$ & $49.6 \pm 12.3$ & $0.0064^{* *}$ \\
\hline
\end{tabular}

a $t$-Test for paired samples.

** Statistically significant difference.

in SRB1 protein levels between control and RTT patients was also confirmed by immunogold labeling analysis (decrease of ca. $75 \%$ ).

\subsection{Increased HNE levels and HNE-SRB1 adducts in RTT fibroblasts}

Increased levels of peroxidation [17] and oxidative stress (OS) [19] have been well documented in RTT patients. For this reason we evaluated the presence of $4 \mathrm{HNE}$, which is a product of lipid peroxidation, the eventual formation of and 4HNE-SRB1 adducts. As shown in Fig. 2A, in RTT fibroblasts there was an increase in 4 HNE protein adducts (ca. $40 \%$, bottom panel) and IP assay (Fig. 2B) evidenced the interaction between SRB1 and 4HNE in RTT fibroblasts respect to the control.

These results were confirmed by double-immunocytochemistry (ICC) assay for SRB1 and HNE. As shown in Fig. 2C, ICC confirmed the low levels of SRB1 in RTT fibroblasts (left column, red color) with a concomitant increase of HNE (Fig. 2C, central column, green color). The co-localization (yellow) appreciable in the right column showed the presence of SRB1-4HNE adducts. The co-localization in RTT fibroblasts was barely perceptible due to the low levels of SRB1. Therefore, as positive control, we treated normal fibroblasts with $\mathrm{H}_{2} \mathrm{O}_{2}$, generated by glucose oxidase (GO), to mimic an OS event. As showed in Fig. $2 \mathrm{C}$ (bottom panel), in this conditions, the control cells responded similarly to RTT fibroblasts evidencing a clear interaction between $4 \mathrm{HNE}$ and SRB1.

\subsection{Increased ubiquitination and 4HNE protein adducts in RTT fibroblasts}

It has been shown that covalent binding of $4 \mathrm{HNE}$ to protein leads to protein modifications that can result in protein ubiquitination and cause its degradation by the proteosome machinery.

In the present experiment we want to determine whether there was an interaction between $4 \mathrm{HNE}$ and the ubiquitin. As shown in Fig. 3A, using the IP approach, RTT fibroblasts presented a clear increase in ubiquitination signal in relation to $4 \mathrm{HNE}$. This was also evident by ICC analysis (Fig. 3B); with the increase of 4HNE levels (left column, green color) and in parallel there was an increased ubiquitination signal (center column, red color). The right column evidenced the co-localization (yellow) suggesting the co-presence
A

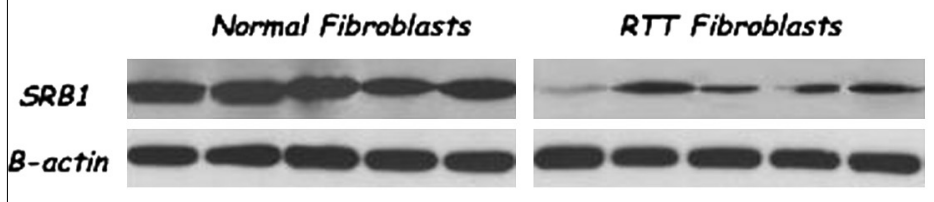

B

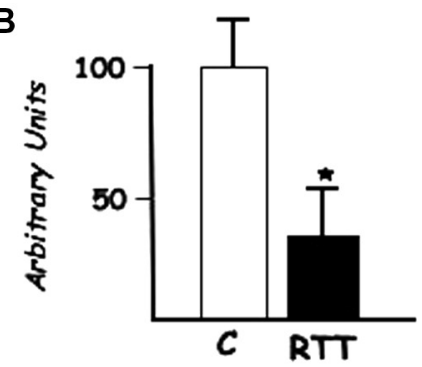

C

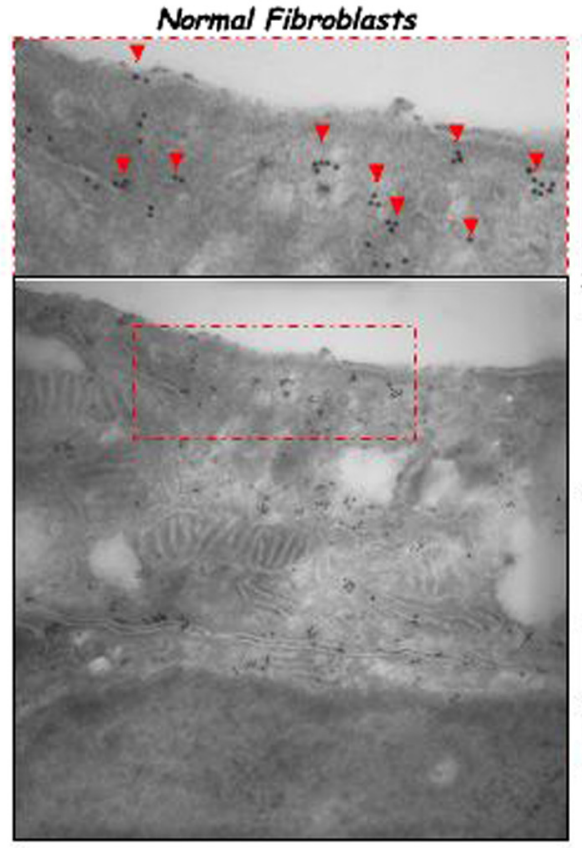

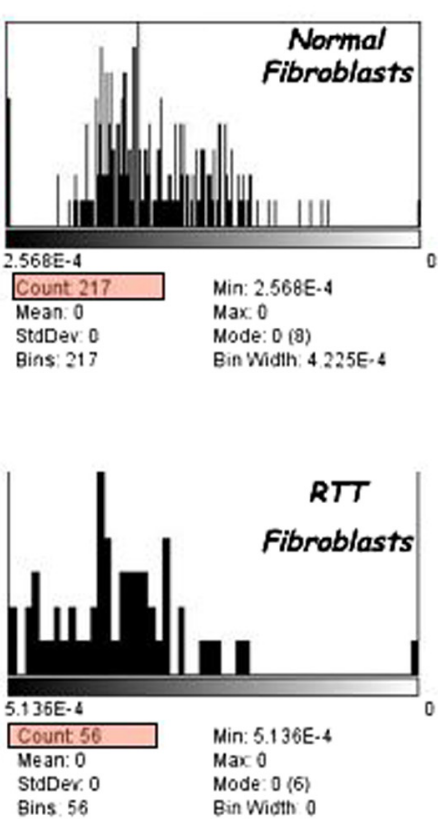

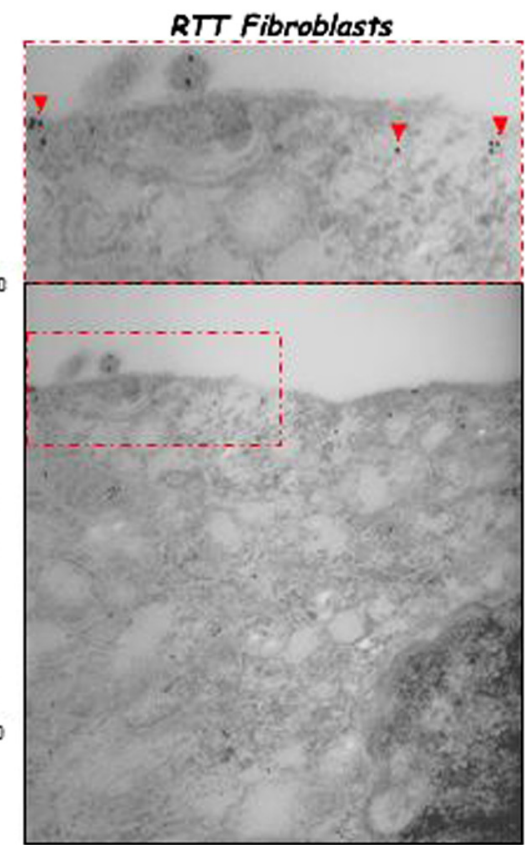

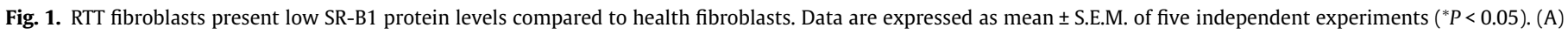

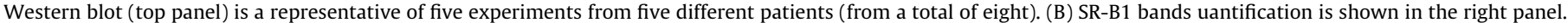

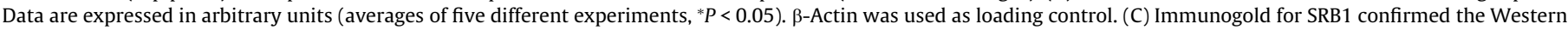
blot data. Each black dot represents the receptor. Original magnification $39000 \times$. 
A

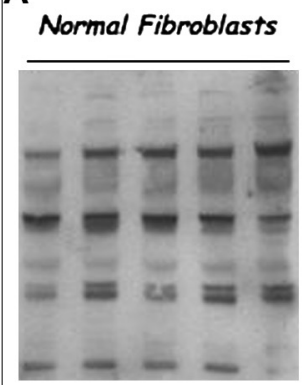

B
IP SRB1
IB HNE

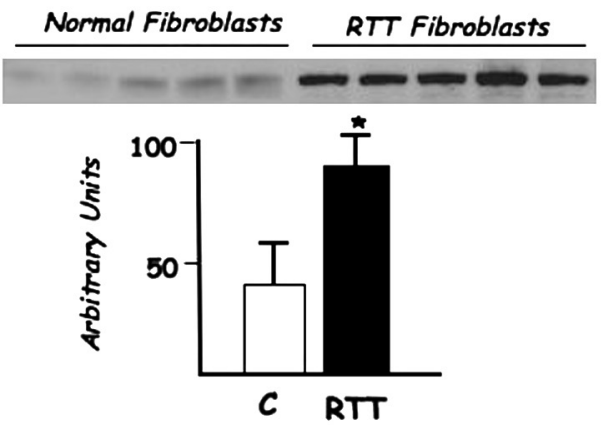

C
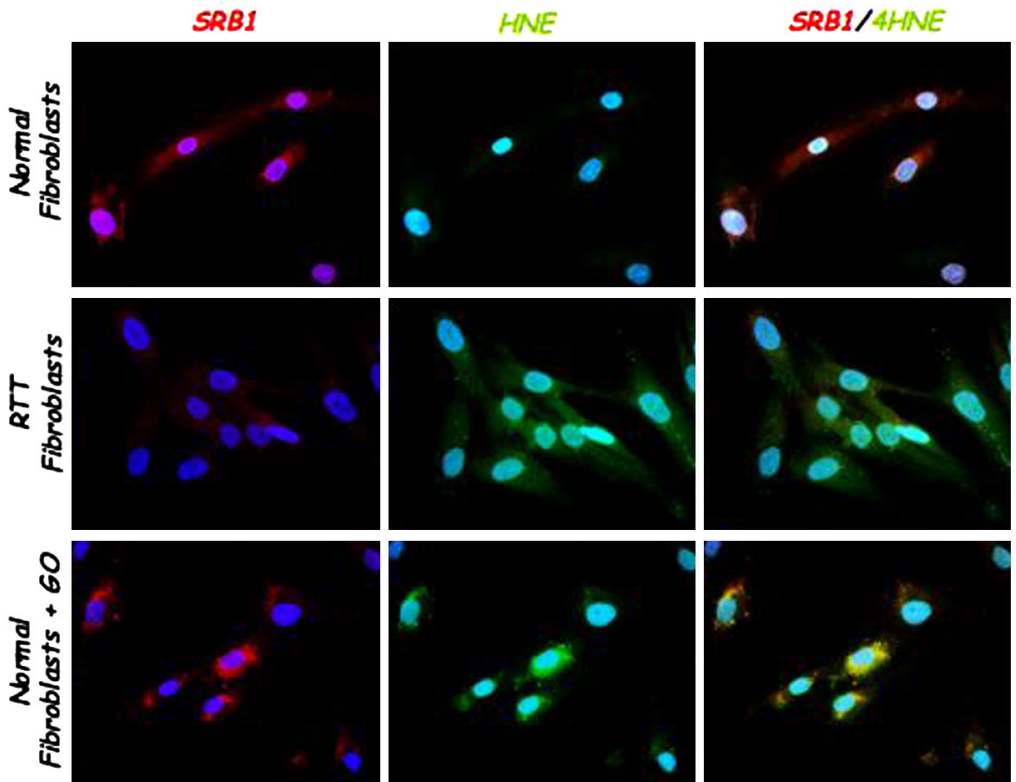

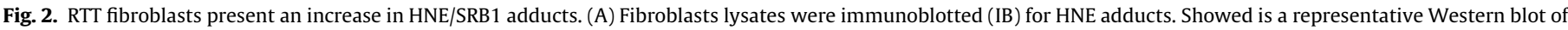

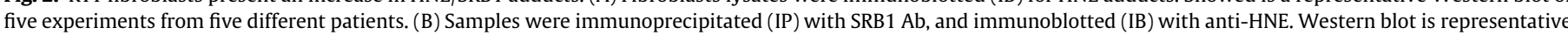

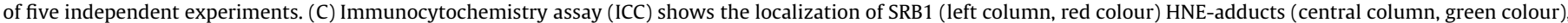
and HNE-SR-B1 adducts (right column, yellow colour). Images are merged in the right panel and the yellow colour indicates overlap of the staining.

A

IP Ub

IB HNE
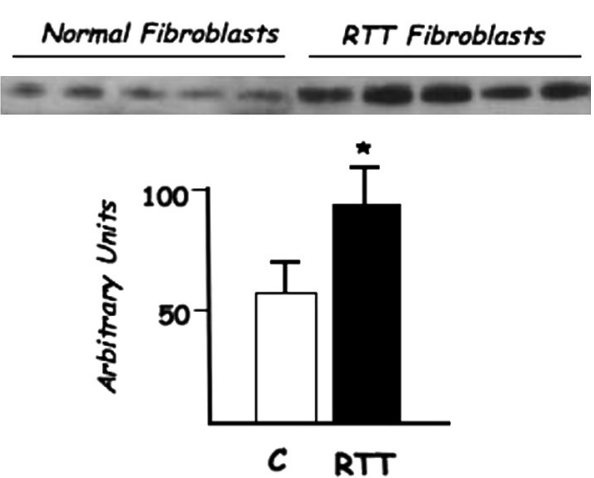

B

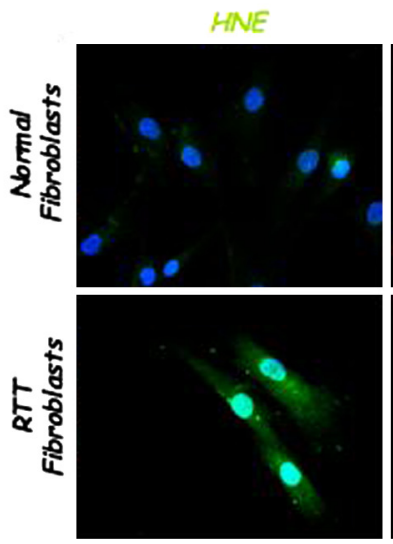

Ub

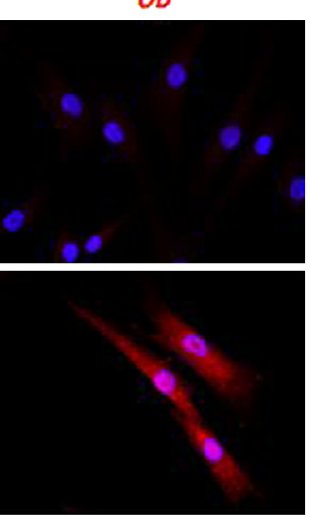

4HNENU

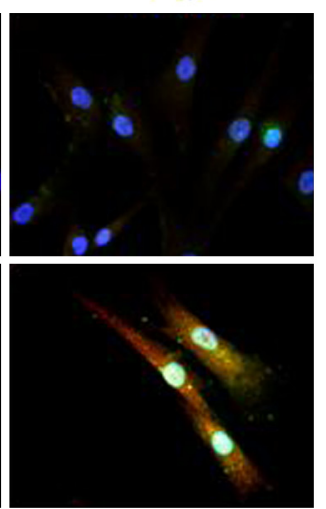

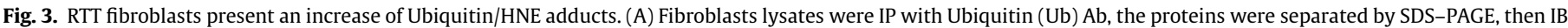

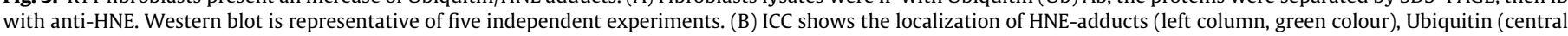
column, red colour) and Ub-HNE adducts (right column, yellow colour). Images are merged in the right panel and the yellow colour indicates overlap of the staining.

of 4 HNE and ubiquitin. This effect was not appreciated in the control fibroblasts.

\subsection{Increases ubiquitination in SRB1-4HNE protein adducts in RTT fibroblasts}

Finally, we decided to evaluate whether the ubiquitination process was involved in the post-translational modification of SRB1 protein in RTT fibroblasts. As shown in Fig. 4A, there was an evident interaction between ubiquitin and SRB1, thus suggesting a process of ubiquitination for SRB1. Using ICC techniques we were able to confirm the low level of SRB1 in RTT fibroblasts (Fig. 4B, left column, green color), the increased ubiquitination (central column, red color) and the co-localization (right column, yellow color) appreciable only in the RTT samples suggesting the formation of SRB1-Ub adducts. The role of the proteosome in SRB1 degradation 
A

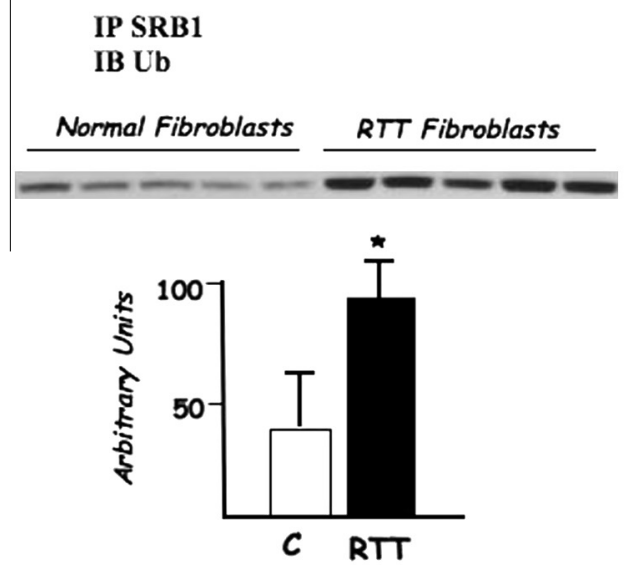

B
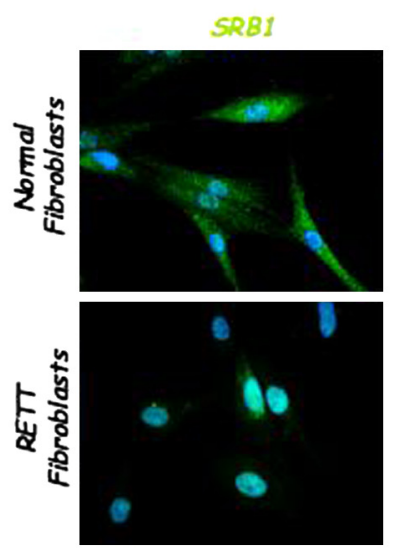
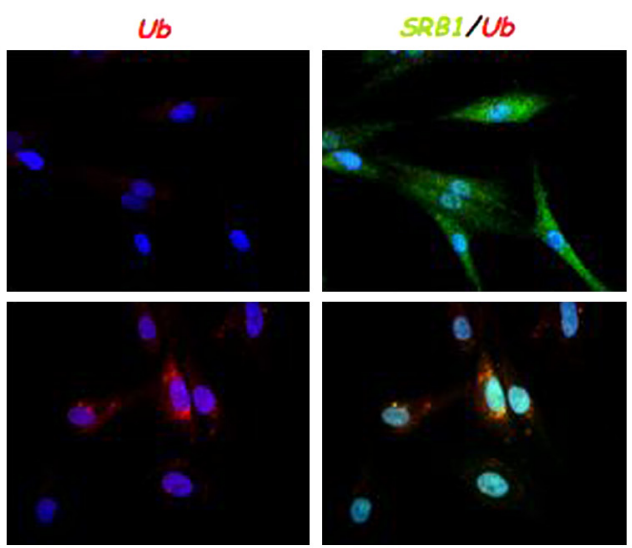

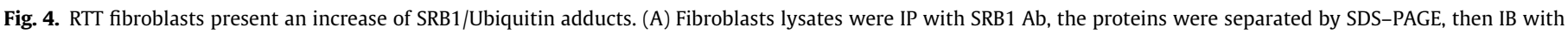

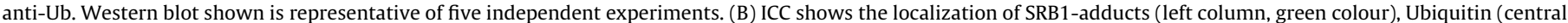
column, red color) and SRB1-Ub adducts (right column, yellow colour). Images are merged in the right panel and the yellow colour indicates overlap of the staining.

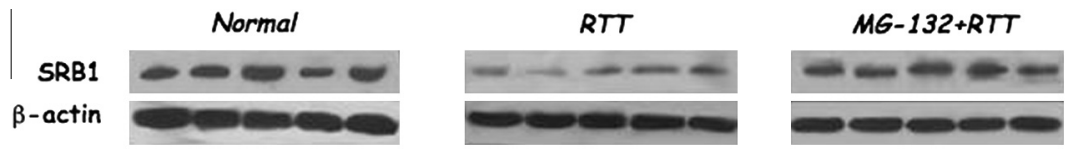

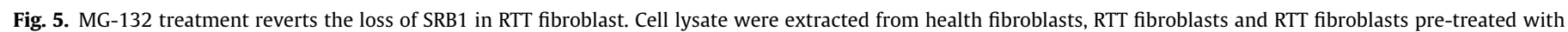
MG-132 (proteosome inhibitor) for $2 \mathrm{~h}$. Western blot is a representative of five experiments from five different patients. $\beta$-Actin was used as loading control.

was confirmed using an inhibitor of the proteosome (MG132) (Fig. 5). When RTT fibroblasts were pretreated with MG132 the loss of SR-B1 was reversed demonstrating that SRB1 is degraded via the proteosome machinery.

\section{Discussion}

In the present study, we have found that RTT patients have an altered plasma lipid profile represented by high levels of HDL and LDL. To our knowledge this is the first report that analyze this feature in RTT. In addition, this work suggests a possible posttranslational mechanism in SRB1 which could explain the coexistence of an altered lipid profile in RTT patients. It has been well documented that SR-B1 mediates the selective uptake of cholesteryl esters from HDL as well as LDL into the cells without internalizing lipoprotein particles [20].

SRB1/KO mice have been established by the laboratories of Van Berkel and Krieger as valuable experimental models for atherosclerosis [21-23]. Their studies have shown that SRB1/KO mice have significant increase in plasma HDL and total cholesterol levels. Furthermore, SRB1/KO animal showed abnormally large HDL particles and can develop atherosclerotic lesions of the arteries and heart with high plasma cholesterol concentrations. Beside these findings from animal studies, no clear pathologies have been so far clearly related to abnormal SRB1 expression, although several other functions for SRB1 have been now recognized [14]. In fact in last few years, the role of SRB1 has been studied under several physio-pathological conditions. For instance SRB1 has been identified as a putative receptor for hepatitis C virus (HCV) [24]. Furthermore, Baranova et al. [25] have shown that the major component of the outer membrane of Gram-negative bacteria (lipopolysaccharide LPS) is able to downregulate both mRNA and protein levels of SRB1 in an NF-kB-mediated mechanism. In addition, a recent study has shown that SRB1 could be also involved in the recognition of dsRNA [26]. These data suggest that SRB1 recognizes danger sig- nals associated with lytic virus infections and from bacterial. Indeed, respiratory viruses produced dsRNA and these infections are associated with the production of ligands released by dead cells probably including modified proteins during the death process. Whether or not the generation of endogenous ligands inhibits immune responses following infection with dsRNA-producing respiratory viruses is still unknown but it is possible to speculate that SRB1 may represent a possible novel target for therapeutic or preventive interventions that aim to control virus-associated immunopathologies. This is in line with unpublished observation from our group $(\mathrm{JH})$ where RTT patients encounter an evident increased frequency of lung infections sometimes leading to their death. SRB1 is also involved in vitamin $\mathrm{E}$ tissue absorption in a mechanism similar to that of cholesterol uptake, indeed it has been shown that SRB1-deficient mice have ca. 50\% less tissue $\alpha$-tocopherol [27] (Fig. 2).

This evidence, together with the finding that forced expression of SRB1 induced cellular uptake of HDL $\alpha$-tocopherol indicates that SRB1 has a role in the uptake of $\alpha$-tocopherol from plasma HDL to tissues. As studies have shown that oxidant-related lung damage is enhanced deficient of vitamin E deficient [28], it is possible that also this aspect is also involved in the pathological features encountered in RTT patients [29]. Thus SRB1 can be considered a multifunctional receptor [14]. Emerging evidences have indicated that SRB1 protein levels are downregulated by oxidative stress (imbalance between oxidants and antioxidants molecules) both from both exogenous (i.e., cigarette smoke and ozone) $[18,13]$ and endogenous (i.e., aging) sources [12]. In the present work, we have shown that the loss of SRB1 is a consequence of post-traslational modifications related to the covalent binding with $4 \mathrm{HNE}$ and to the subsequent ubiquitination, which led to SRB1 degradation by the proteosome. Indeed, the use of the proteosome inhibitor MG132 reversed the effect.

The binding of ubiquitin to a protein serves as a signaling mechanism for degradation of the selected protein. The rate of protein 
degradation is altered in neuropathologies such as Alzehimer, Parkinson and Algelman and Rett syndrome (Lehman NL 2009, Acta Neurotpahol) where the existence of OS has been well demonstrated.

The presence of systemic OS in RTT patients has been well established [19,16,17]. 4HNE which, is formed from arachidonic acid or other unsaturated fatty acids following free radical attack can bind, by Michael addition to proteins, particularly to cysteine, hystidine, or lysine residues [30]. For this reason, 4HNE-PAs are considered not only a reliable marker of OS but thanks to its ability to form adducts to the proteins, $4 \mathrm{HNE}$ has also a biological impact by changing protein functions.

Interestingly, a previous report by our group has shown the presence of radiological features in RTT patients, closely resembling those of respiratory bronchiolitis-associated interstitial lung disease (RB-ILD), a lung pathology typically related to CS [29]. To this regard, exposure to CS has been previously shown to induce the loss of SRB1 protein both in vivo and in vitro $[12,13]$ and in particular, the cell study has evidenced an increased SRB1 ubiquitination, as we have shown in RTT skin fibroblasts [18].

Therefore SRB1 can be a molecular bridge between RTT and OS mediated lung diseases. Moreover, it is possible that the protein fate observed for SRB1 could be shared by several other proteins not yet known at this time.

The results of this study point out several outcomes. Firstly, the loss of SRB1 is a previously unrecognized feature of RTT. Secondly, down-regulation of SRB1 could explain some of the clinical features of RTT such as hyperlipidemia, lung infections and respiratory bronchiolitis. Thirdly, by documenting the presence of $4 \mathrm{HNE}$ (marker of oxidative stress), we further confirm at the tissue level the coexistence of a systemic redox status alteration, previously documented by us in blood samples from RTT patients [15]. Finally, it is important to underline that primary cultured skin fibroblasts isolated from patients prove to be a good model for a better understanding of the molecular aspects linking the $\mathrm{MeCp} 2$ gene mutation to the disease phenotypic expression.

\section{Acknowledgments}

We thank the Kiwanis Club of Siena for their support and we wish to dedicate this paper in memoriam of Mr. Giuseppe Ciupi, past President of the Club. The research has been funded by Tuscany Region and by the Toscana Life Sciences.

\section{References}

[1] Rett, A. (1966) Uber ein eigartiges hirnatrophisches Syndrom bei Hyperammoniamie in Kindesalter. Wien Med. Wochenschr. 116, 723-738.

[2] Amir, R.E., Van den Veyver, I.B., Wan, M., Tran, C.Q., Francke, U. and Zoghbi, H.Y. (1999) Rett syndrome is caused by mutation in X-linked MECP2, encoding methyl-CpG-binding protein 2. Nat. Genet. 23, 185-188.

[3] Nazeer, A. and Ghaziuddin, M. (2012) Autism spectrum disorders: clinical features and diagnosis. Pediatr. Clin. North Am. 59 (1), 19-25.

[4] Guideri, F., Acampa, M., Hayek, Y. and Zappella, M. (2005) Effects of acetyl-Lcarnitine on cardiac dysautonomia in Rett syndrome: prevention of sudden death? Pediatr. Cardiol. 26 (5), 574-577.

[5] Rohdin, M., Fernell, E., Eriksson, M., Albåge, M., Lagercrantz, H. and KatzSalamon, M. (2007) Disturbances in cardiorespiratory function during day and night in Rett syndrome. Pediatr. Neurol. 37 (5), 338-344.

[6] Wiest, M.M., German, J.B., Harvey, D.J., Watkins, S.M. and Hertz-Picciotto, I. (2009) Plasma fatty acid profiles in autism: a case control study. Prostaglandins, Leukotrienes Essent. Fatty Acids 80 (4), 221-227.

[7] Report of Expert Panel on Blood Cholesterol Levels in Children and Adolescents. (1991). U.S. Department of Health and Human Services, National Institutes of Health. National Heart, Lung, and Blood Institute. National Cholesterol Education Program. NIH Publication No. 91-2732.
Abnormalities in lipid profile in ASDs patients have been shown by several investigators.

[8] Dziobeck, I., Gold, S.M., Wolf, O.T. and Convit, A. (2007) Hypercholesterolemia in Asperger syndrome: independence from lifestyle, obsessive-compulsive behavior, and social anxiety. Psychiatry Res. 149, 321-324.

[9] Landien, M., Baghael, F., Rosmond, R., Goran, H., Bjorntrop, P. and Eriksso, E. (2004) Dyslipidemia and high waist-hip ratio in women with self-reported social anxiety. Psychoneuroendocrinology 29, 1037-1046.

[10] Monteleone, P., Santonastaso, P., Pannuto, M., Favaro, A., Caregaro, L., Castaldo E., Zanetti, T. and Maj, M. (2005) Enhanced serum cholesterol and triglycerides levels in bulimia nervosa: relationships to psychiatric co-morbidity, psychopathology and hormonal variables. Psychiatry Res. 134 (3), 267-273.

[11] Kim, E.K., Neggers, Y.H., Shin, C.S., Kim, E. and Kim, E.M. (2010) Alterations in lipid profile of autistic boys: a case control study. Nutr. Res. 30 (4), 255-260.

[12] Valacchi, G., Vasu, V.T., Yokohama, W., Corbacho, A.M., Phung, A., Lim, Y., Aung H.H., Cross, C.E. and Davis, P.A. (2007) Lung vitamin E transport processes are affected by both age and environmental oxidants in mice. Toxicol. Appl. Pharmacol. 222 (2), 227-234.

[13] Valacchi, G., Davis, P.A., Khan, E.M., Lanir, R., Maioli, E., Pecorelli, A., Cross, C.E. and Goldkorn, T. (2011) Cigarette smoke exposure causes changes in scavenger receptor B1 level and distribution in lung cells. Int. J. Biochem. Cell Biol. 43 (7), 1065-1070.

[14] Valacchi, G., Sticozzi, C., Lim, Y. and Pecorelli, A. (2011) Scavenger receptor class B type I: a multifunctional receptor. Ann. N.Y. Acad. Sci. 1229, E1-E7.

[15] De Felice, C., Signorini, C., Leoncini, S., Pecorelli, A., Durand, T., Valacchi, G., Ciccoli, L. and Hayek, J. (2012) The role of oxidative stress in Rett syndrome: an overview. Ann. N.Y. Acad. Sci. 1259, 121-135.

[16] Leoncini, S., De Felice, C., Signorini, C., Pecorelli, A., Durand, T., Valacchi, G., Ciccoli, L. and Hayek, J. (2011) Oxidative stress in Rett syndrome: natural history, genotype, and variants. Redox Rep. 16 (4), 145-153.

[17] Pecorelli, A., Ciccoli, L., Signorini, C., Leoncini, S., Giardini, A., D’Esposito, M., Filosa, S., Hayek, J., De Felice, C. and Valacchi, G. (2011) Increased levels of 4HNE-protein plasma adducts in Rett syndrome. Clin. Biochem. 44 (5-6), 368371.

[18] Sticozzi, C., Belmonte, G., Pecorelli, A., Arezzini, B., Gardi, C., Maioli, E., Miracco, C., Toscano, M., Forman, H.J. and Valacchi, G. (2012) Cigarette smoke affects keratinocytes SRB1 expression and localization via $\mathrm{H}_{2} \mathrm{O}_{2}$ production and HNE protein adducts formation. PLoS One 7 (3), e33592.

[19] De Felice, C., Ciccoli, L., Leoncini, S., Signorini, C., Rossi, M., Vannuccini, L., Guazzi, G., Latini, G., Comporti, M., Valacchi, G. and Hayek, J. (2009) Systemic oxidative stress in classic Rett syndrome. Free Radical Biol. Med. 47 (4), 440-448.

[20] Ikonen, E. (2006) Mechanisms for cellular cholesterol transport: defects and human disease. Physiol. Rev. 86 (4), 1237-1261.

[21] Kuipers, F. and Van Berkel, T.J. (2003) Differential effects of scavenger receptor $\mathrm{BI}$ deficiency on lipid metabolism in cells of the arterial wall and in the liver. J. Biol. Chem. 26, 23699-23705.

[22] Rigotti, A., Trigatti, B.L., Penman, M., Rayburn, H., Herz, J. and Krieger, M. (1997) A targeted mutation in the murine gene encoding the high density lipoprotein (HDL) receptor scavenger receptor class B type I reveals its key role in HDL metabolism. Proc. Natl. Acad. Sci. USA 23, 12610-12615.

[23] Trigatti, B., Rayburn, H., Viñals, M., Braun, A., Miettinen, H., Penman, M., Hertz, M., Schrenzel, M., Amigo, L., Rigotti, A. and Krieger, M. (1999) Influence of the high density lipoprotein receptor SR-BI on reproductive and cardiovascular pathophysiology. Proc. Natl. Acad. Sci. USA 16, 9322-9327.

[24] Heo, T.H., Lee, S.M., Bartosch, B., Cosset, F.L. and Kang, C.Y. (2006) Hepatitis C virus E2 links soluble human CD81 and SR-B1 protein. Virus Res. 121 (1), 58-64.

[25] Baranova, I., Vishnyakova, T., Bocharov, A., Chen, Z., Remaley, A.T., Stonik, J. Eggerman, T.L. and Patterson, A.P. (2002) Lipopolysaccharide down regulates both scavenger receptor B1 and ATP binding cassette transporter A1 in RAWcells. Infect. Immun. 70, 2995-3003.

[26] Dieudonné, A., Torres, D., Blanchard, S., Taront, S., Jeannin, P., Delneste, Y. Pichavant, M., Trottein, F., Gosset, P., Hybertson, B.M., Leff, J.A., Beehler, C.J., Barry, P.C. and Repine, J.E. (2012) Scavenger receptors in human airway epithelial cells: role in response to double-stranded RNA. PLoS One 7 (8), e41952.

[27] Mardones, P., Strobel, P., Miranda, S., Leighton, F., Quiñones, V., Amigo, L. Rozowski, J., Krieger, M. and Rigotti, A. (2002) Alpha-tocopherol metabolism is abnormal in scavenger receptor class B type I (SR-BI)-deficient mice. J. Nutr. 132 (3), 443-449.

[28] Hybertson, B.M., Leff, J.A., Beehler, C.J., Barry, P.C. and Repine, J.E. (1995) Effect of vitamin E deficiency and supercritical fluid aerosolized vitamin E supplementation on interleukin-1-induced oxidative lung injury in rats. Free Radical Biol. Med. 18 (3), 537-542.

[29] De Felice, C., Guazzi, G., Rossi, M., Ciccoli, L., Signorini, C., Leoncini, S., Tonni, G., Latini, G., Valacchi, G. and Hayek, J. (2010) Unrecognized lung disease in classic Rett syndrome: a physiologic and high-resolution CT imaging study. Chest 138 (2), 386-392.

[30] Poli, G., Biasi, F. and Leonarduzzi, G. (2008) 4-Hydroxynonenal-protein adducts: a reliable biomarker of lipid oxidation in liver diseases. Mol. Aspects Med. 29 (1-2), 67-71. 